University of Windsor

Scholarship at UWindsor

7-2009

\title{
Using self-concept theory to identify and develop volunteer leader potential in healthcare
}

\author{
Francine K. Schlosser \\ Odette School of Business, University of Windsor \\ Deborah McPhee \\ Andrew Templer
}

Follow this and additional works at: https://scholar.uwindsor.ca/odettepub

Part of the Business Commons

\section{Recommended Citation}

Schlosser, Francine K.; McPhee, Deborah; and Templer, Andrew. (2009). Using self-concept theory to identify and develop volunteer leader potential in healthcare. Advances in Health Care Management, 8 , 21-47.

https://scholar.uwindsor.ca/odettepub/120

This Article is brought to you for free and open access by the Odette School of Business at Scholarship at UWindsor. It has been accepted for inclusion in Odette School of Business Publications by an authorized administrator of Scholarship at UWindsor. For more information, please contact scholarship@uwindsor.ca. 
Using self-concept theory to identify and develop volunteer leader potential in healthcare

Francine Schlosser, Ph.D.

Associate Professor, Management

Odette School of Business

University of Windsor

Windsor, Ontario,

Canada, N9B 3P4

Email: fschloss@uwindsor.ca

Tel.: 519-253.3000 x3107

Fax: 519-973-7073

Deborah M. Zinni, Ph.D (Contact Author)

Associate Professor, Faculty of Business

Brock University

500 Glenridge Avenue, Taro Hall 416

St. Catharines, Ontario,

Canada, L2S 3A1

Email: dzinni@ brocku.ca

Tel.: 905-688-5550 x3908

Fax: 905-984-4188

Andrew Templer, Ph.D.

Professor of Management

Odette School of Business

University of Windsor

Windsor, Ontario,

Canada, N9B 3P4

Email: templer@uwindsor.ca

Tel.: 519-253-3000 x3159

Fax: 519-973-7073

A previous version of this paper was presented at Academy of Management, Healthcare Interactive Papers, August 2008

\section{PROPER CITATION:}

Schlosser, F. K., Zinni, D. and Templer, A. (2009). Using self-concept theory to identify and develop volunteer leader potential in healthcare. Biennal Review of Healthcare Management: Meso Perspectives. Advances in Healthcare Management, 8, 21-47. 
Using self-concept theory to identify and develop volunteer leader potential in healthcare

\begin{abstract}
Resource constraints in the Canadian publicly funded healthcare system have created a need for more volunteer leaders to effectively manage other volunteers. Self concept theory has been conceptualized and applied within a volunteer context, and the views of healthcare stakeholders, such as volunteers, volunteer leaders and supervisors, triangulated to form an understanding of the attitudes and behaviors of volunteer leaders. We propose that leaders are differentiated from others by how they view their roles in the organization, and their ability to make a difference in these roles. This interpretation can be informed by self-concept theory because each individual's notion of self-concept influences how employees see themselves, how they react to experiences and how they allow these experiences to shape their motivation. A small case study profiles a volunteer leader self-concept that includes a proactive, learning-oriented attitude, capitalizing on significant prior work experience to fulfill a sense of obligation to the institution and its patients, and demands a high level of respect from paid employees.
\end{abstract}




\section{Introduction}

Most non-profit organizations rely upon volunteer support to reach their goals. The value of hospital volunteering has an estimated payoff of almost seven times the cost to manage volunteer labor (2004, p. 23). The importance of volunteering to charities extends beyond free labor, to building confidence in that institution (Bowman, 2004). This image is important to the success of any healthcare institution, in fact more than 60 percent of 778 participants in a recent study attributed altered views of nursing facilities to volunteering (Keith, 2005).

Despite such recognized benefits it has become more difficult to retain and recruit volunteers. Volunteers have more demands placed upon their time, as they work longer hours at home and at work. Additionally, organizations face stricter requirements in the selection of appropriate volunteers, such as legal responsibilities regarding criminal background checks as well as privacy of information. These considerations limit the pool and expertise of volunteers.

Budget cutbacks in government-funded healthcare have also resulted in fewer paid personnel who can co-ordinate volunteer work. A recent study of 28 hospitals using more than 2 million volunteer hours annually (Handy \& Srinivasan, 2005), concluded that organizational demand for volunteer labor is a decreasing function of their costs. Thus, the willingness of hospitals to use volunteer labor diminishes as the cost to manage the volunteer force increases. These issues have increased the demand for volunteer leaders who can manage a team of volunteers. This demand is critical in healthcare, but is also felt across the non-profit sector.

The success of non-profit organizations hinges upon the effective and co-ordinated behaviors of volunteer leaders. Leaders can be characterized by their strength of personality or character (Bowden, 1926) and in their activities inducing group change (Cooley, 1902; Mumford, 1906/1907). Leaders are also able to influence others toward a common goal 
(Stogdill, 1950). We propose that leaders are differentiated from others by how they view their roles in the organization, and their ability to make a difference in these roles. This interpretation can be informed by self-concept theory because each individual's notion of self-concept influences how employees see themselves, how they react to experiences and how they allow these experiences to shape their motivation. Organizations that rely heavily upon volunteer leaders must better understand this relationship between leader self-concept and the volunteer environment. Self-concept contributes to how individuals are able to recognize their inherent strengths and weaknesses so that organizations are better able to meet the needs of their respective volunteers by reflecting this understanding in training and assignment of duties.

Other researchers have conceptualized in general terms how the self concept of leaders and of followers influence each other (Robert G. Lord \& Brown, 2001; R. G. Lord, Brown, \& Freiberg, 1999). These general conceptualizations will have more value to organizational decision-makers if they are examined within specific organizational situations. We suggest that the burgeoning importance of volunteer leader development in the resource-constrained voluntary sector provides some impetus to consider how self-views might affect the leadership potential of ageing volunteers. Volunteers' views of their roles are shaped by both individual and relational level processes. Accordingly, this paper first conceptualizes the attributes and behaviors that distinguish effective volunteer leaders and then applies this model using a case study methodology. In addition we explore how a volunteer leader self-concept develops, thus informing the actions that institutions can take to encourage the emergence of new volunteer leaders. Volunteering Vocation and Commitment 
As a broad definition, volunteerism is defined as "any service to the community given without payment through a group or organization" (Warburton \& Terry, 2000, p. 249). At a more general level, the definition of a volunteer is "an individual who is unpaid and gives freely of his or her time" (see (Brudney \& Kellough, 2000; Hartenian, 2007; A. Wilson \& Pimm, 1996). Wilson (2000) noted the importance of commitment to the volunteer role and to the organization and concluded that volunteering must be viewed within the concept of self identity, that is, how volunteers see themselves as people who help others. He described the three main reasons why volunteers withdraw from volunteering: (1) their efforts are unrecognized, (2) there is a poor fit between their interests and volunteer roles, and (3) their efforts to help clients/patients are limited by lack of autonomy. These reasons point to a need for fulfillment as a potential reason for volunteerism. Volunteers will feel fulfilled if their efforts are recognized and aligned with individual goals and if they are given autonomy.

Volunteers' identification with the organization and their internalization of its goals are related to what volunteers are willing to contribute (Farmer \& Fedor, 2001; Katz \& Kahn, 1966/1978; Pearce, 1993). Previous research has explained that volunteers are driven by both altruism and egoism motives (Bowman, 2004). Keith (2003) concluded that differences in volunteer motivation and skills were explained by age, education and prior volunteer experience. Esteem needs, such as acknowledgement, recognition and self-actualization, motivate volunteers. The way that individuals perceive their personal interests and contributions may provide insights as to how to construct a volunteer self-concept. A volunteer's self-view is framed by the fulfillment of their own goals and obligation to the organization's goals. The following section describes self-concept according to previous theorists and is used to construct the conceptualization of volunteer and volunteer leader self concept. 


\section{Constructing a Volunteer Leader Self Concept}

In their review of past literature, Markus and Wurf (1986) p. 299 concluded that the selfconcept could be defined as "a set or collection of images, schemas, conceptions, prototypes, theories, goals, or tasks" held by an individual. Markus and Wurf (1986) highlighted the selfconcept as a mediator and regulator of behavior and contended that, "It interprets and organizes

self-relevant actions and experiences; it has motivational consequences, providing the incentives, standards, plans, rules and scripts for behavior; and it adjusts in response to challenges from the social environment." However, the non-specific nature of self-concept makes it difficult to test empirically, and creates a need to split the self-concept into different levels for practical field analysis. Lord et al. (1999) suggest that field researchers should distinguish stable and highly accessible schemas from other more obscure and variable schemas. The more accessible schemas determine which level of self-identity is salient at any given time.

To clarify, volunteers have multiple definitions of self, divided into two levels of social inclusion (Brewer \& Gardner, 1996; R. G. Lord et al., 1999; Markus \& Wurf, 1986). The first level of self focuses inward upon the individual, with social inclusion limited to comparisons with others. The second level expands social inclusion by focusing outward on how the individual relates to others.

The Individual Self

At the individual level, a person defines the self as a separate unique entity. Individuals operating at this level develop feelings of self-worth by comparing their own traits to others. The individual self-identity is predicated upon the idea of a person's uniqueness and separation from others. Markus and Wurf (1986, p. 315) have suggested that, at the individual level, "the 
self-concept mediates intrapersonal processes, which include self-relevant information processing, affect regulation and motivation processes".

First, self-relevant information involves a social comparison to others or to different situations implying a judgment of personal capability (Bandura, 1997). In a study of aging female volunteer leaders who sought out planning and developing workshops to help them organize and manage their groups, Burden (2000) noted the significance of a developmental perspective when theorizing volunteering. These women felt more capable after experiencing the workshop. Thus, discussion of the volunteer leader role involves comparing their accountabilities and developmental needs relative to others.

Second, affect regulation describes feelings of personal control, through emotional selfcontrol. Volunteers in a healthcare context must manage significant stressors related to seriously ill and dying patients, grieving and concerned families, and stressed-out employees (Dein \& Abbas, 2005). Active volunteers demonstrate more empathic concern (Bekkers, 2005) and altruism (Mowen \& Sujan, 2005). A recent study of volunteers in an AIDS organization concluded that volunteers who showed empathic concern and perspective taking believed that their volunteer experiences had more value (Stolinski, Ryan, Hausmann, \& Wernli, 2004). Consequently, how leaders view their abilities to deal with this stress relative to others will shape their willingness to continue to volunteer as a post-employment leisure activity.

Finally, intrinsic motivation is related to the concept of role satisfaction because individuals will view themselves in comparison to other possible selves or other people. Previous researchers have concluded that volunteer involvement (total time volunteered) is predicted by satisfaction (Davis, Hall, \& Meyer, 2003) and that motivation is strongly correlated to satisfaction (Reeser, Berg, Rhea, \& Willick, 2005). Older volunteers experience greater increases 
in life satisfaction over time as a result of their volunteer hours than their younger counterparts (Van Willigen, 2000) as well as improved physical and mental health (Lum \& Lightfoot, 2005). Additionally, older volunteers who do not experience significant roles in other life relationships (such as partner, employment and marital) develop their psychological well-being through volunteering (Greenfield \& Marks, 2003). In a longitudinal study of 144 volunteers, Omoto, Snyder and Martino (2000), found that younger volunteers tend to be motivated by and achieve outcomes related to interpersonal relationships. This is in contrast with older volunteers who are more likely to be motivated by service and obligation to the community. Consequently, when desiring to retain and develop older volunteers as leaders, organizations must understand volunteer attitudes and behaviors related to motivation and satisfaction.

The Interpersonal Self

At a second level of self-concept, researchers have discussed the importance of the interpersonal (relational) self to the understanding of human relationships. For example, Brewer and Gardner (1996) defined the interpersonal self within the context of relationships to others. At the relational level, the self develops through interaction or membership. For example, Lord et al. (1999) suggested that the relational self-concept will be influenced by a leader's feedback. This relational self could also include the "reflected self", or the way that the individual perceives others to feel about him/her (R. G. Lord et al., 1999, p. 4). Similarly, in symbolic interactionist literature, Cooley (1902) developed the concept of the "looking glass self" which reflects a picture of the self relative to others, specifically how individuals sense that others view their actions or roles.

To summarize, both individual and relational levels of self-concept develop over time. The individual self-view derives through comparison with an alternate self, such as a past or 
future conception of one's self or even a referent person. For example, volunteers may view their unpaid contribution in terms of the education and skills they developed in their previous paid careers. For example, a retired automotive executive may wish to utilize previous corporate leadership experiences in a unpaid volunteer assignment in a healthcare facility. In contrast, the relational self is defined in terms of how others view the individual. Accordingly, volunteer leaders define their contribution through their interaction with other hospital stakeholders, such as patients, paid employees, other volunteers and institutions such as the union and the hospital management.

\section{Distinguishing Leaders from Others}

Business researchers have defined leadership as personality traits, actions, context and relationships. For example, earlier research pertaining to leadership might be considered as a nexus of group change, activity and process (Cooley, 1902; Mumford, 1906/1907), as a strength of personality or character (Bingham, 1927; Bowden, 1926) and as a way to influence others toward a common goal (Stogdill, 1950). Bass (1990) relates this influence to the use of persuasion, power and the creation of structure.

We can build upon these ideas to conceptualize how volunteer leaders may be distinguished from other volunteers at an individual and relational level. Figure 1 depicts elements of individual and relational self-concept relevant to leaders and other volunteers. Effective volunteers may view themselves in relation to their volunteering activities as both obligated and fulfilled. However, we propose that volunteer leaders act as a nexus of change and activity by being proactive in situations where other volunteers may choose a passive reaction. We suggest that leaders are aware of the personal sources of power and this awareness will shape 
their conceptualization of self at the individual level. The relational self-concept is developed through the use of this power to influence other volunteers toward the institution's goal. We explain this by applying a case study methodology.

Figure 1 about here

Methods

A qualitative study was undertaken, utilizing a case study methodology, in order to better explore the different attitudes and behaviors of volunteer leaders and followers. Employing a case study methodology enables a researcher to closely examine the data within a specific context. In most cases, a case study method selects a small geographical area or a very limited number of individuals or organizations as the subjects of study. Case studies, in their true essence, explore and investigate contemporary real-life phenomenon through detailed contextual analysis of a limited number of events or conditions, and their relationships. Yin (1984) defines the case study research method "as an empirical inquiry that investigates a contemporary phenomenon within its real-life context; when the boundaries between phenomenon and context are not clearly evident; and in which multiple sources of evidence are used". The case study method has been used effectively in a number of fields including sociology and within government, management and education. Therefore, a case study allowed us to select an 
organization that had many volunteers, and had already begun to develop a team structure with volunteer leaders.

Study Context

A hospital context was chosen for this study because volunteer followers and leaders play a crucial role in delivering care to a broad section of society. Hospital volunteerism has been the focus of some previous research, but has focused upon motivation for volunteering (e.g., LiaoTroth, 2005) or recently the economic implications of volunteers in the resource-constrained health sector (Handy \& Srinivasan, 2004, 2005).

Data were collected from volunteer followers and leaders and employees in a large Canadian hospital. This hospital had played an important community role for 125 years. Founded in 1888 by an Order of Catholic nuns, within 20 years the hospital had established a School of Nursing that later became part of local post-secondary institutions. In 1994, the hospital merged with two other religious-based hospitals and consolidated to two locations within the city. Although the hospital provides universal healthcare, the religious nature of this institution is worth noting because it may amplify the vocational expectations of employees, volunteers and patients. The hospital has continued to experience funding cutbacks and financial difficulties. At the time of the study, 500 individuals actively volunteered at the hospital, co-ordinated by one paid staff member (the "volunteer co-ordinator") whose primary responsibility was to recruit, coordinate and retain volunteers. Another important point is that this particular hospital is highly unionized, which has implications for those wishing to volunteer. For example, unionized workers may perceive that a volunteer is performing the work that should be given to a paid unionized worker.

Sample 
The case samples of 'leaders' and 'other' volunteers were selected in consultation with the paid volunteer co-ordinator. As the sole person in the organization responsible for recruitment and development of volunteers, the perceptions of this co-ordinator reflected the expectations of the organization. The volunteer co-ordinator differentiated leaders from others by identifying volunteers that had decreased her personal management load by taking on additional responsibilities. With the help of the co-ordinator we were also able to identify volunteers who exemplified long-term, reliable volunteer commitment. Accordingly, we were able to assess participant attitudes and behaviors that shape these desired outcomes. Therefore, this sample is a purposeful sample. The value of this type of sample is that it can provide unique cases that are especially informative (Neuman, 2004). All participants identified by the paid volunteer co-ordinator, were contacted and asked if they would like to participate. All those contacted agreed to meet with the researchers.

Table 1 describes the demographics of the study participants. Most of the study participants were over 50 years of age, and were collecting some form of retirement or disability pension. This aligns with previous research on volunteer leaders. For example, Edwards, Mooney and Heald (2001) concluded that older community volunteers were more likely than student volunteers to assume responsibility for planning and coordinating services. Thus the age of the participants in this study are representative of the general volunteer population.

Table 1 about here

\section{Data Collection}


Data were collected over two months in a series of focus groups and interviews. First a two-hour long focus group was conducted with volunteer leaders, followed by a second with 'other' volunteers. Additionally, paid employees who supervised volunteers were interviewed for 30 minutes in person or by telephone. All interviews were tape-recorded with the permission of the interviewees. The questionnaires are available for perusal from the lead researcher.

\section{Data Analysis}

The tape-recorded interviews were content analyzed with the assistance of the qualitative software program NVivo. NVivo is a powerful program for coding and interpreting textual data. The initial coding was performed by a research assistant and was audited by the author. The narratives were coded using standard qualitative analysis techniques (Creswell, 1998). The minor discrepancies that existed between the coders were resolved by the coders together examining the data. The cases were initially coded at the sentence level with each substantive sentence assigned to one or more of various themes.

\section{Development of Themes and Construction of a Volunteer Leader Self-Concept}

The data were analyzed to identify attitudes and behaviors that distinguished volunteer leaders from other volunteers. Additionally, we investigated the relationship between paid supervisors and volunteers and how each assessed volunteer effectiveness and satisfaction. Review of verbal and non-verbal communication patterns in the focus group discussions revealed common themes related to both the individual and relational self. This process allowed us to understand volunteer leadership using a framework of self-concept. Leaders and Other Volunteers 
This section highlights individual and relational self-concept themes found in the data, using quotes to profile the differences in attitude and behavior between volunteer leaders and other volunteers. Table 2 profiles differences that are related to each aspect of the individual and interpersonal self and identifies whether connections exist to proactive and passive behaviors and to the use of power and influence.

Based on the content analysis and previous literature, we sorted the data into the individual level themes of self-relevant information processing, affect regulation, and motivation, noted by Markus and Wurf (1986). This approach highlighted differences in how the volunteer leader and follower focus groups expressed thoughts and experiences specifically in the areas of training and development, coping strategies, and their previous work experiences.

Table 2 about here

Differences were noted in individual themes related to duties and accountabilities relative to other volunteers and paid employees. Other volunteers noted their duty was to willingly cooperate and be part of a team. In contrast, volunteer leaders were willing to take on managing tasks (such as scheduling and training) and displayed leadership attributes (such as willingness to stand up for the rights of volunteers).

Volunteer leaders viewed their duties differently from other volunteers, noting the importance of training and scheduling tasks and heightened unit responsibilities. A volunteer leader noted,

“We need at least 4 people a day, and if someone can't make it, then I have to call someone else or I will come in myself”. 
This same sentiment was echoed by another volunteer leader who noted "If somebody does not show up or I cannot find someone else then I am it. Sometimes it is three days a week. We have some new volunteers but they are not all very responsible".

As previously discussed, leadership has been defined as a nexus of group change, activity and process, strength of character and a way to influence others toward a common goals by being proactive. Although agreeing on a lesser accountability than paid work, volunteer leaders in the study more often defined their role based on what needed to get done, whereas other volunteers were more likely to view it as secondary to paid employees. By demonstrating the willingness to get the job done, leaders were influencing others towards a common goal of exemplary "patient care". For example, a leader noted,

"If a nurse asks you to do something you might do it, but if the nurse asks a porter, then they may say that it is not my job, but I as a volunteer would never say it is not my job".

In addition to setting an example of completing whatever task is presented, these leaders are also demonstrating extra-role behavior. In addition to patient care, volunteer leaders sometimes found themselves in other peripheral activities of the hospital such as in the lost and found, records, or even the coffee and gift shops. Although they are not core, peripheral activities are often staffed with volunteers and are important to the effective functioning of the organization. As one volunteer noted of a volunteer leader:

"She is also in charge of the lost and found ...... It is a big job. If it sits around for a long time and it is not clean she will take it home and wash it and clean it and mend it and then she will take the clothes over to our church that is in a poor area 
and then they sort the clothes into different groups and gives them to needy families".

The differences in the way that leaders and other volunteers defined their volunteer roles were also reflected in how they described situations in the hospital that involved effectiveness and compassion. Both described effectiveness using terms like compassion, self-less, social conscious, thoughtful, and providing a hug or a hand to hold. Additionally they described their own effectiveness and compassion relative to the effectiveness of paid employees. The focus group of volunteer leaders voiced high expectations of paid employees. For example, a volunteer leader described a time when she was waiting with family members for 11 hours, during a patient's serious, day long surgery. As the volunteer's shift was about to end, the volunteer leader asked a nurse to call up to the operating room to find out how much longer the surgery would last. She noted, "I get chills telling you that they [the nurses] wouldn't do it for me.... but I had to leave and I could hardly go back and tell the patient's family that I'm leaving now. They [the family] said,' what about my mother?' Why wouldn't they [the nurses] have feelings for that family"?

In contrast, other volunteers appeared to have less expectation that the effectiveness of paid staff would be linked to compassion,

“Like if you're in a room with patients, and you sense that they need to talk or have tears in their eyes, you sit down and ask them what's wrong, you have that time whereas a nurse may not".

Differences in the way that volunteer leaders and other volunteers regulated their emotions were linked to personal development and decision-making. A volunteer leader who 
performed a task that was perceived to be a nurse's responsibility, remedied her lack of experience by taking a course for helping people cope with dying. Other volunteer leaders also held leadership executive roles in the volunteer association. In contrast, non-leader volunteers stressed the importance of "fit" with their volunteering role, rather than personal development. As one volunteer indicated, 'I think if you match the person's attributes to the job, that's the best, they'll be good at it. It will be a trial and error process, depending on the person's personality." Matching an individual's skills to a particular job is certainly advantageous to the hospital, however, volunteer effectiveness in this instance would be about an individual going where they are needed, as opposed to where they may feel they are better suited - an attribute that volunteer leaders hold as important to effective volunteerism. In yet another example, a volunteer indicates that they want to be told what to do, rather than make decisions, "Here it's kind of nice because someone can just tell you what they'd like you to do and you just do it and you're not in the planning."

Previous experience was viewed as important to being an effective volunteer by leaders, other volunteers, and paid employees. However, in leaders, this referent self played a greater role in shaping their sense of personal power, leading to a lengthy discussion in the volunteer leader focus group. During this discussion, a leader noted

“Going back to 'We are just a volunteer', I think staff has to realize that before we came to volunteer we had a position in the community. B-- was an engineer, a highly respected position. I get the impression [from some employees] that we are just somebody off the street volunteering. I think I sort of shook a few minds because I was helping a patient up and one of the nurses said it was not my job 
and then $C$-- who is the manager down there who was one of my students said that

'D-- has been a nurse here for so many years, she knows what she is doing'”.'

Other volunteers fit their prior skill-sets to the tasks given. They were not as comfortable in going beyond their assigned volunteer duties even if they were well qualified to do so. For example,

“Your past skills count for a lot... Because I'm a skilled tradesperson, they're [paid employees] very sticky about what your job is and who does what... Going out of your way is okay, but not if you're offending people".

The Volunteer Leader Relational Self

The data profiled in Table 2 also included themes that informed our understanding of the relational self-concept of volunteers and volunteer leaders. In this table we note how volunteer leaders and other volunteers differ in how they see themselves reflected by other hospital stakeholders. Relationships with unionized personnel (eg. such as porters), paid employees (eg. such as nurses), patients, volunteer peers and the institution, shaped the volunteer leader and follower self-perception.

Throughout our focus group meetings and discussions with various participants, union sensitivities were consistently discussed. Both unionized and non-unionized employees are wary of the activities of the volunteers, concerned that their jobs may be in jeopardy. The thinking is that if a volunteer does the porter job, then there would be no need to employ the porter. The same sentiment does not hold true for jobs requiring more skill such as for nurses. As one participant noted, "The higher the skill set, those people are not insecure they appreciate us. The lower the skill set they are insecure". What this suggests is that leaders must be politically astute in how to work around porters, or jobs where workers may feel insecure towards the 
volunteers. In essence they will do what is necessary to get the job done but not by offending anyone. For example, in their relationship with the union, volunteer leaders were more likely to feel that they should take a leadership role to resolve conflict. Quoting a leader,

"When a doctor gave me something to do they went to management. And another thing I should have done... they said to me, do you want to meet with the union leader and I said, look, I'm just a volunteer and the volunteer services lady went to the meeting, but I think I was wrong. I think I should have went to the meeting. Now when I look back to what had happened, because the person sent was also in the union, I should have gone.....I would now [speak for and defend her team] but I thought that being a volunteer... I didn't think I should have to go into that kind of thing... I am not here to argue. I wanted to let someone else handle it".

Further, several other volunteers noted conflicting situations, showing how sensitive they needed to be. As one participant notes,

“There's one thing you have to remember about volunteering, and this we can't take the place of a paid worker... and... not infringe on union conditions"”.

Yet another participant states,

"I make sure I say it...I am M-- the volunteer. I went through a lot of difficulties with upsetting the porters. It is a shame that I have to watch what I do with the porters around".

So even though leaders and volunteers were sensitive to certain unionized employees' insecurities, they felt that the needs of the patient must be fully considered. Therefore, in instances related to employees such as porters, volunteer leaders would make sure these employees were not around before engaging in activities directly associated with their duties, not 
as a way to undermine the employees' responsibilities, but for the sake of patient care. For example, one leader told us,

"When the porters leave, then I tell the girls that they can go over and pick up the patients, but they don't do it while they [the porters] are there because they are threatened and it is really a shame. Because there are a lot of other things they could be doing, but we still do it. You have to play your cards right." Regarding their relationship with paid employees, participants in the volunteer leader focus group discussed their feelings that paid employees did not respect volunteers, for example:

"When I started volunteering 28 years ago, the staff did not appreciate having volunteers around they thought it was taking work away from them and some of them in the elevators would ask why would you want to work for free? But now they do appreciate it".

In contrast, other volunteers discussed their beliefs that paid employees valued and respected their volunteering efforts, "I heard the nurses tell the patients that they don't know what they would do without the volunteers".

Their relationships with patients most strongly defined the volunteering motivations and vocational identity of volunteer leaders and other volunteers. A volunteer leader noted, "It helped me to be in the recovery room and the O.R.... that I am not the only one going through different things. I could help people and I could relate to what they were going through. It really is nice to volunteer in the recovery room because the families really do appreciate it".

A volunteer (non-leader) noted, 
"I have a child care degree, a bit of university and a college degree. I started out as a mental patient myself, and now I feel I have the empathy for these people".

Both volunteer leaders and other volunteers described patient satisfaction as the most important measure of their effectiveness as volunteers. Feedback and interaction with patients developed a positive volunteer self-view, apparent in these quotes:

Volunteer Leader: "When a patient says thank you it makes your day. We don't need someone from the first floor to give you a pin or a pat on your back. It is self satisfaction.

Volunteer (non-leader): By the thanks you get. Just when they say 'you're an angel'. Because it's their comments that show how effective you are".

The self-concepts of volunteer leaders and non-leaders were also shaped through relationships with other volunteers, forming a culture amongst the volunteers. For example, a feeling of belonging related to volunteer uniforms was evident in this leader's quote:

"We have new shirts and I have had many comments from people who are not appreciative of them switching the color from pink to blue. They say 'we have known you as the pink ladies for decades and now all of a sudden we are the blue ladies. We walked in looking for the pink ladies".

Leaders discussed the importance of meeting to communicate important issues such as security during the SARS outbreak, whereas other volunteers were more likely to describe relationships with other volunteers in terms of gatherings and lunches. The leaders were assuming their leadership duties, taking care of everyone to ensure continued patient care, where volunteers focused on the social aspect associated with their volunteer role. 
The last theme regarding relational self, involved their relationship with the institution. Both volunteer leader and non-leader participant relationships with this hospital originated through previous experiences as patients, employees or community members that were then strengthened by current volunteering experiences. For example, different leader participants noted that,

Participant 1: "older family members were served very well here so I thought it would be a good place to give back”.

Participant 2: "I was more familiar with this institution. As a child if we were ever hurt, this is the hospital that we would go to, or when my parents had surgeries this is where they were".

Participant 3: "You walk in and everyone sincerely smiles and says hi".

However, through discussion all the volunteers, leaders and otherwise, were aware of the value they contributed to the bottom line of the hospital, noting that there were huge cost savings with them volunteering. This denotes that the volunteers understood their role in the context of the overall organizational effectiveness, and took responsibility for their role in patient care and comfort.

Leader Volunteer Influence Behaviors

The Volunteer Leader focus group had a lengthy discussion about their informal role modeling efforts to influence people outside the hospital to become volunteers. Examples include:

Participant 1 - "Well one nurse one day in the elevator said she was ready to retire and she said I think I am going to come back and volunteer because of you. 
She said to me "I am paid so much an hour and you ladies are not paid anything and there you are smiling and there we are with the long face......"

Participant 2-No people leave and you don't hear from them. I go to the retirement luncheon twice a year. I have tried to get people to come back and they are just not willing to come back and I think that is a great sadness.

However, the focus groups did not highlight typical relationship themes between leaders and other volunteer team members. There were no quotes that exemplified vertical tactics (downward from the volunteer leaders nor upward tactics from the other volunteers) nor horizontal influence tactics. For example, leaders highlighted the frustrations of working with high school aged volunteers ( 40 volunteer hours were mandated in the local high school system). These student volunteers were not perceived to have the same level of fulfillment and obligation to their volunteering role. References were repeatedly made to the lack of commitment from these students, as well as a lack of maturity. However, neither the volunteer leaders nor the other longer term volunteers in the focus groups described any attempt to influence the student volunteers toward more effective behaviors and goals while admitting that younger people could make a difference in brightening up the lives of some of the patients with their warm smiles. Furthermore, the comments showed a line drawn in the sand between the older and the younger volunteers. As mentioned previously, there is a bifurcation in the volunteer composition - they are either younger students, or aging volunteers, with few in-between. This bifurcation of volunteers is quite disturbing as it reflected potential issues in developing a sustainable chain of strong and effective volunteers.

A few leaders described requests by the other volunteers for the leaders to use their leadership role and power to intervene in group conflicts. In spite of this, the leaders did not find 
an opportunity to do so, because the volunteer scheduling made it difficult to meet as a team. Also, although the hospital paid staff had identified the participants in the first focus group as effective volunteer leaders, and the second focus group as effective volunteers, almost all of the second group was unaware of the presence of team leaders. Further investigation into this phenomena indicated that volunteer leaders were relegated to a few areas of the institution, and that their role was based on long-term tenure and their particular knowledge in certain areas. Their main duty entailed the scheduling of volunteers, thus taking the onus away from the understaffed volunteer co-ordinator's office, who were in need of assistance. Essentially these leaders had no say in the type of volunteers who worked in their respective departments, nor did they play in role in the performance management of the volunteers. They did however liaise with the departments on any concerns that may arise between volunteers, workers and patients, however, they do not have the power to resolve organizational issues, forwarding them to the volunteer co-ordinator. This further indicates the lack of influence exerted by those in volunteer team leader roles. This is particularly concerning because the lack of formal structure in the volunteer hierarchy can lead to confusion and undermine the effective functioning of volunteer leaders.

\section{Discussion}

This case study examined the differences in attitudes and behaviors linked to the selfconcepts of "effective" volunteer leaders and other volunteers. To summarize (based on focus group consensus), they differed at an individual level of self concept by (a) their duties as volunteer leader or other volunteer, demonstrated by leaders having heightened responsibility for covering volunteer needs, (b) their active or passive views of volunteer activities relative to paid responsibilities (c) their conflict coping techniques, specifically with leaders choosing more 
learning oriented techniques (d) their sense of personal power and efficacy related to prior work experiences. At the relational level, leaders and followers differed in (a) how their self-efficacy was reflected in employee appreciation or lack of appreciation, and (b) how their volunteer or volunteer leader role shaped a sense of self reflected in how other volunteers interacted with them (socially versus task oriented).

Volunteer leaders and followers were similar in their identification with other volunteers and the value they placed on serving patient needs. They were also likely to have a positive prevolunteering experience with the hospital. Attitudes expressed in both focus groups reflected a knowledge of institutional norms and familiarity with the job content, gained through long-term experience with the hospital. This long-term experience encompassed both pre-volunteer and volunteer encounters. Followers and leaders placed importance on working within the system to increase patient care. Much discussion centered on how volunteers were required to balance patient and employee needs for volunteer help with other structured roles in the organization. For example, limits were placed on their roles by either a lack of professional expertise (nursing was done by registered nurses) and by collective agreements.

Similar to Keith (2003), the behaviors and attitudes of most effective leader volunteers interviewed in the current study reflected skills learned as employees, and specifically knowledge of the organizational culture and routines of the hospital. One participant had not worked at the hospital, but had worked in a unionized shop, and this helped him to understand the union-volunteer relationship. Women who had been stay-at-home moms, could not as easily understand this relationship, opting to ensure the care of the patients was never compromised. Additionally, more than half of the volunteers and volunteer leaders were currently or had 
previously volunteered with other organizations, and this demonstrated their commitment to volunteering, and potential competition for their volunteer involvement.

Study participants, from both leader and follower volunteer perspectives, experienced a strong relational attachment to the hospital. This attachment was formed from prior experiences with the hospital, for example, as employees, patients, or relatives of patients. This indicates that they experienced a strong relational social exchange prior to joining the institution on a volunteer basis. However, there was also substantial discussion about the management problems at the hospital and how other retired employees refused to consider post-employment volunteering. This suggests that pre-volunteering experiences with the institution and specifically the type of relationship that emerges may influence the development of volunteer organizational commitment and the decision to volunteer.

Leaders and other volunteers unanimously perceived volunteering at this organization to require a deep commitment to the patients. For example, they discounted the effectiveness of students who volunteered in order to meet community service hours (required by high schools and some government programs). Paid employees who supervised volunteers noted that they assessed volunteer effectiveness by asking other supervisors and workers for assessment, or by quantifying the value of their unpaid work. In contrast, volunteers and leaders measured their own effectiveness by patient satisfaction. Consequently, a social exchange also developed between volunteers and their clients - patients and relatives.

This case study flagged problems with the volunteer leaders. Without the use of direct influence on other volunteers, they were unable to direct all volunteers on a common path toward the same goal and commitment. The hospital's volunteer retention and attraction issues, and the 
aging volunteer base may stem from the lack of influence tactics used by volunteer leaders with new student volunteers and with the other longer term volunteers.

\section{Using Self Concept Theory to Identify and Develop Volunteer Leader Potential}

This case holds implications for hospitals and other large formalized institutions in the identification and management of volunteer leaders. Volunteer leaders have heightened expectations of effectiveness regarding both paid and unpaid workers. Thus there are indications that volunteer leaders are sensitive to being a part of a team with high standards. Leaders believed that compassion was a part of everyone's role, and not just an extra duty delegated to volunteers because paid staff didn't have time. Volunteers were more likely than paid employees in this study to describe effectiveness and compassion as being central to patient care, as well as patient care being the ultimate measure of effectiveness. This study implies that institutions who encourage paid employees to delegate the role of compassion and hand-holder to volunteers may risk alienating both the experienced leader volunteer, and the patients themselves who expect "care" to be exemplified in paid healthcare professionals. However, in the face of diminishing funds, the role the volunteer's duties are increasing and their participation in assisting with the paid-work of employees may also be a symptom of the increased work being downloaded to employees who are expected to take on larger workloads. Therefore, whatever role the volunteer takes on should be based on the peripheral aspects of other's job(s), and not on the main tasks. This goal can only be achieved by instituting clearly defined job descriptions for both the volunteer leader and their respective volunteers. However, consideration has to be made to keep these job descriptions as generic as possible to ensure that there is flexibility for the volunteer leaders to make appropriate judgment calls as the task 
demands, and to keep the task of continued upgrading of job descriptions to a minimum in order to keep costs in-line with budgetary constraints.

The study also indicates that institutions should consider the previous job experiences of volunteers when choosing leaders. While it was clear that the leaders we spoke to were ideally suited to their respective areas, there is an increased need to utilize more leaders in the hospital. As such, an internal posting system should be developed to encourage the growth in this area. It was evident that a number of volunteers would not want such a role, but there were others that had come from high level positions in their previous working lives who might value this leadership role, and who probably bring a lot of value-added because of their prior experience. However, an increase in the amount of volunteers indicates that better recruitment and selection of leaders is warranted. In a workplace setting human resource managers commonly use personality testing (Barrick \& Mount, 1993; Le, Oh, Shaffer, \& Schmidt, 2007)and structured job interviews (Olmstead, 2007) to select paid workers. The same concepts can be utilized to ensure person-job fit for unpaid workers.

One area of concern was the misuse of student volunteers. Since it is difficult to attract a large pool of volunteers, students offer an available pool of recruits. Unfortunately, as indicated in our interviews, they are not seen as effective as others demonstrating a lack of commitment, no loyalty, and a "get me out of here as soon as possible" attitude that does not meet with the attitudes of effective volunteers. Special student assignments should be identified that will either meet the person-job fit with students, and or short term assignments to be fulfilled away from the general public. With volunteer leaders having appropriate authority, they can discipline students who do not wish to take on the required roles and behaviors needed. Without successful endorsement on completion of their volunteer assignment, volunteer leaders can chose to either 
pass or fail the student. A failure would result in the student not achieving their volunteerism hours, and having to repeat some aspect of it. Alternatively, if the student is not fulfilling the needs of the requirement, they could be dropped from the volunteerism program. Therefore, a program that awards points of merit, fulfilling the required hours, and fulfilling identified action items, could be a way to ensure students are more effective volunteers. Assigning student volunteer leaders may also be effective to encourage students to take on leadership roles, which are useful for them when they apply to other jobs and may encourage them to be better volunteers.

More notably, and concerning, is that as the healthcare industry continues to experience shortages in paid workers, unpaid workers now become critical to healthcare delivery (American Society of Training and Development, 2007). Therefore, it is of paramount importance that appropriate human resource and employee development programs, once relegated to full-time paid employees, also be part of mainstream training for unpaid workers. They must also support the development needs and credibility of volunteer leaders in dealings with paid employees, perhaps through social events, and joint training and development opportunities. Training programs will need to be developed in order to facilitate the transitional role for those becoming leaders, or for those who to increase their knowledge and expertise in leadership. Modeling effective leader behavior should be incorporated as part of the training. Self-learning programs can also be incorporated, to alleviate the time demands of volunteers that may not be available.

Finally, the study highlights the limitations associated with appointing volunteer team leaders to just manage administrative tasks. These volunteer leaders have demonstrated proactive behaviors and personal power bases that could be used to influence other volunteers, at both mature and junior stages of volunteering. They may demonstrate managerial talents but still 
require leadership coaching. As such, mentoring programs, coupled with training and feedback should be instituted.

One final aspect is a reward system. Through discussions with paid staff, we learned that formal rewards consisted primarily of pins presented at an annual volunteer event, paid lunches and parking. We consistently heard from volunteer leaders that the accolades they received were enough to keep them motivated and satisfied. They made comparisons to other institutions that did not do these things. Therefore, it is important that the hospital continue its stated traditions, but also consider other programs such as volunteer leader of the month selected amongst all other volunteer leaders in the hospital, as well as for volunteer of the month in each of their respective departments. As well, senior management needs to have a presence and conduct department visits on a consistent basis, thanking the volunteers whenever they see the expected behavior.

Limitations and Implications for Future Research

This case analysis was conducted at only one healthcare institution, and our results are most appropriately generalized to other institutions within a similar context; specifically those with a large and formalized group of volunteers and a unionized workforce. Both of these conditions might influence the scope and content of volunteer duties, and the need for volunteer leaders.

Measurement of effectiveness in other volunteering contexts may pose challenges for future research. The exploratory study identified attitudinal differences between paid staff and volunteers. Paid staff were more likely to assess volunteer effectiveness based upon monetary contribution, or supervisory evaluation. A similar perspective has been used in previous research, for example (Farmer \& Fedor, 2001) measured effectiveness by how much money and 
time were given by the volunteer, and using overall assessments provided by the volunteer administrator. These measures are limited because they do not assess the level of client satisfaction. Indeed, volunteers in the exploratory study noted that their effectiveness should be measured by customer appreciation.

The qualitative nature of this study is inherently subjective. Qualitative analysis always entails making choices on explanatory models and options and alternative explanations might apply. However, we have used our best interpretation of the relevant literature to choose the models and frameworks that will give the paper a strong conceptual anchor.

Future research should build upon the findings of this qualitative research to investigate methods that might be used to measure the effectiveness of volunteer leaders and other volunteers across North America. It would be important to understand the differences between a publicly funded healthcare system, and one that is not. Further, the notion of working in a unionized setting presents many constraints on a volunteer's ability to do their work, and so it would be advantageous to understand how volunteer leaders and other volunteers function in non-unionized settings. Additionally, it would be important to understand the motivations of younger volunteers, who may engage in this activity beyond just educational credit requirements. This would help to create a sustainable stable of volunteers.

\section{Conclusion}

To conclude, this research has examined how volunteer leaders and other volunteers differ in their volunteer self-concept. Self concept theory has been applied within a volunteer context, and the views of different stakeholders triangulated to form an understanding of the attitudes and behaviors of volunteer leaders. . 
In summary, our study profiles a volunteer leader self-concept that includes a proactive, learning-oriented attitude, capitalizing on significant prior work experience to fulfill a sense of obligation to the institution and its patients, and demands a high level of respect from paid employees. Without effective volunteers, healthcare institutions would not successfully fulfill their societal obligations to high-quality healthcare. Therefore, volunteerism, with volunteer leaders is an important program requiring further research to help these organizations reach their stated-goals. 


\section{References}

American Society of Training and Development. (2007). Healthcare Searches for Retention Cure. $T+D, 61(6), 16$.

Bandura, A. (1997). Self-efficacy: The Exercise of Control. New York: W.H. Freeman.

Barrick, M. R., \& Mount, M. K. (1993). Autonomy as a moderator of the relationships between the big five personality dimensions and job performance. Journal of Applied Psychology, 78, 111-118.

Bass, B. M. (1990). Bass \& Stogdill's Handbook of Leadership. New York: The Free Press.

Bekkers, R. (2005). Participation in voluntary associations: Relations with resources, personality, and political values. Political Psychology, 26(3), 439-454.

Bingham, W. (1927). Leadership. In H. Metcalf (Ed.), The psychological foundations of management. New York: Shaw.

Bowden, A. (1926). A study of the personality of student leaders in the United States. Journal of Abnormal and Social Psychology(47), 534-539.

Bowman, W. (2004). Confidence in charitable institutions and volunteering. Nonprofit and Voluntary Sector Quarterly, 33(2), 247-270.

Brewer, M. B., \& Gardner, W. L. (1996). Who is this "We"? Levels of collective identity and self-representations. Journal of Personality and Social Psychology, 71, 83-93.

Brudney, J. L., \& Kellough, J. E. (2000). Volunteers in state government: Involvement, management and benefits. Nonprofit and Voluntary Sector Quarterly, 29(10), 111-130.

Burden, J. (2000). Community building, volunteering and action research. Loisir \& SocieteSociety and Leisure, 23(2), 353-370.

Cooley, C. (1902). Human nature and the social order. New York: Scribners.

Creswell, J. W. (1998). Qualitative Inquiry and Research Design: Choosing Among Five

Traditions. Thousand Oaks, CA: Sage Publications.

Davis, M. H., Hall, J. A., \& Meyer, M. (2003). The first year: Influences on the satisfaction, involvement, and persistence of new community volunteers. Personality and Social Psychology Bulletin, 29(2), 248-260.

Dein, S., \& Abbas, S. Q. (2005). The stresses of volunteering in a hospice: a qualitative study. Palliative Medicine, 19(1), 58-64.

Edwards, B., Mooney, L., \& Heald, C. (2001). Who is being served? The impact of student volunteering on local community organizations. Nonprofit and Voluntary Sector Quarterly, 30(3), 444-461.

Farmer, S. M., \& Fedor, D. B. (2001). Changing the focus on volunteering: an investigation of volunteers' multiple contributions to a charitable organization. Journal of Management, 27(2), 191-211.

Greenfield, E., \& Marks, N. (2003). Volunteering as a moderater of the mental health effects of role-identity absence in older adulthood: Evidence from midus. Gerontologist, 43, 325325.

Handy, F., \& Srinivasan, N. (2004). Valuing volunteers: An economic evaluation of the net benefits of hospital volunteers. Nonprofit and Voluntary Sector Quarterly, 33(1), 28-54.

Handy, F., \& Srinivasan, N. (2005). The demand for volunteer labor: A study of hospital workers. Nonprofit and Voluntary Sector Quarterly, 34(4), 491-501. 
Hartenian, L. S. (2007). Nonprofit agency dependence on direct service and indirect support volunteers: An empirical investigation. Nonprofit Management and Leadership, 17(3), 319-334.

Katz, D., \& Kahn, R. (1966/1978). The social psychology of organizations. New York: Wiley.

Keith, P. M. (2003). Interests and skills of volunteers in an ombudsman program: Opportunities for participation. International Journal of Aging \& Human Development, 57(1), 1-20.

Keith, P. M. (2005). Correlates of change in perceptions of nursing facilities among volunteers. Journal of Applied Gerontology, 24(2), 125-141.

Le, H., Oh, I.-S., Shaffer, J., \& Schmidt, F. (2007). Implications of methodological advances for the practice of personnel selection: How practitioners benefit from meta-analysis. Academy of Management Perspectives, 21(3), 6-15.

Liao-Troth, M. A. (2005). Are they here for the long-haul? The effects of functional motives and personality factors on the psychological contracts of volunteers. Nonprofit and Voluntary Sector Quarterly, 34(4), 510-530.

Lord, R. G., \& Brown, D. J. (2001). Leadership, values and subordinate self-concepts. The Leadership Quarterly, 12, 133-152.

Lord, R. G., Brown, D. J., \& Freiberg, S. J. (1999). Understanding the dynamics of leadership: the role of follower self-concepts in the leader/follower relationship. Organizational Behavior and Human Decision Processes, 78, 167-203.

Lum, T. Y., \& Lightfoot, E. (2005). The effects of volunteering on the physical and mental health of older people. Research on Aging, 27(1), 31-55.

Markus, H., \& Wurf, E. (1986). The dynamic self-concept: A social psychological perspective. Annual Review of Psychology, 3, 299-337.

Mowen, J. C., \& Sujan, H. (2005). Volunteer behavior: A hierarchical model approach for investigating its trait and functional motive antecedents. Journal of Consumer Psychology, 15(2), 170-182.

Mumford, E. (1906/1907). Origins of Leadership. American Journal of Sociology, 12, 216-240.

Neuman, W. L. (2004). Basics of Social Research (Vol. 138-139). Boston: Allyn and Bacon/Pearson.

Olmstead, J. (2007). Predict future success with structured interviews. Nursing Management(March), 52-53.

Omoto, A. M., Snyder, M., \& Martino, S. (2000). Volunteerism and the Life Course: Investigating Age-Related Agendas for Action. Basic and Applied Social Psychology, 22(3), 181-197.

Pearce, J. L. (1993). Volunteers: The Organizational Behavior of Unpaid Workers. London: Routledge.

Reeser, J. C., Berg, R. L., Rhea, D., \& Willick, S. (2005). Motivation and satisfaction among polyclinic volunteers at the 2002 Winter Olympic and Paralympic Games. British Journal of Sports Medicine, 39(4).

Stogdill, R. (1950). Leadership, membership and organization. Psychological Bulletin, 47, 1-14.

Stolinski, A. M., Ryan, C. S., Hausmann, L. R. M., \& Wernli, M. A. (2004). Empathy, guilt, volunteer experiences, and intentions to continue volunteering among buddy volunteers in an AIDS organization. Journal of Applied Biobehavioral Research, 9(1), 1-22.

Van Willigen, M. (2000). Differential benefits of volunteering across the life course. Journals of Gerontology Series B-Psychological Sciences and Social Sciences, 55(5), S308-S318. 
Warburton, J., \& Terry, D. J. (2000). Volunteer decision making by older people: A test of a revised theory of planned behavior. Basic and Applied Social Psychology, 22, 245-257.

Wilson, A., \& Pimm, G. (1996). The tyranny of the volunteer. The cae adn feeding of voluntary workforces. Management Decision, 34(4), 24-35.

Wilson, J. (2000). Volunteering. Annual Review of Sociology, 26, 215-240.

Yin, R. K. (1984). Case Study Research: Design and Methods (First ed.). Beverley Hills, CA: Sage Publications. 
Figure 1

\section{Volunteer Self-Concept}

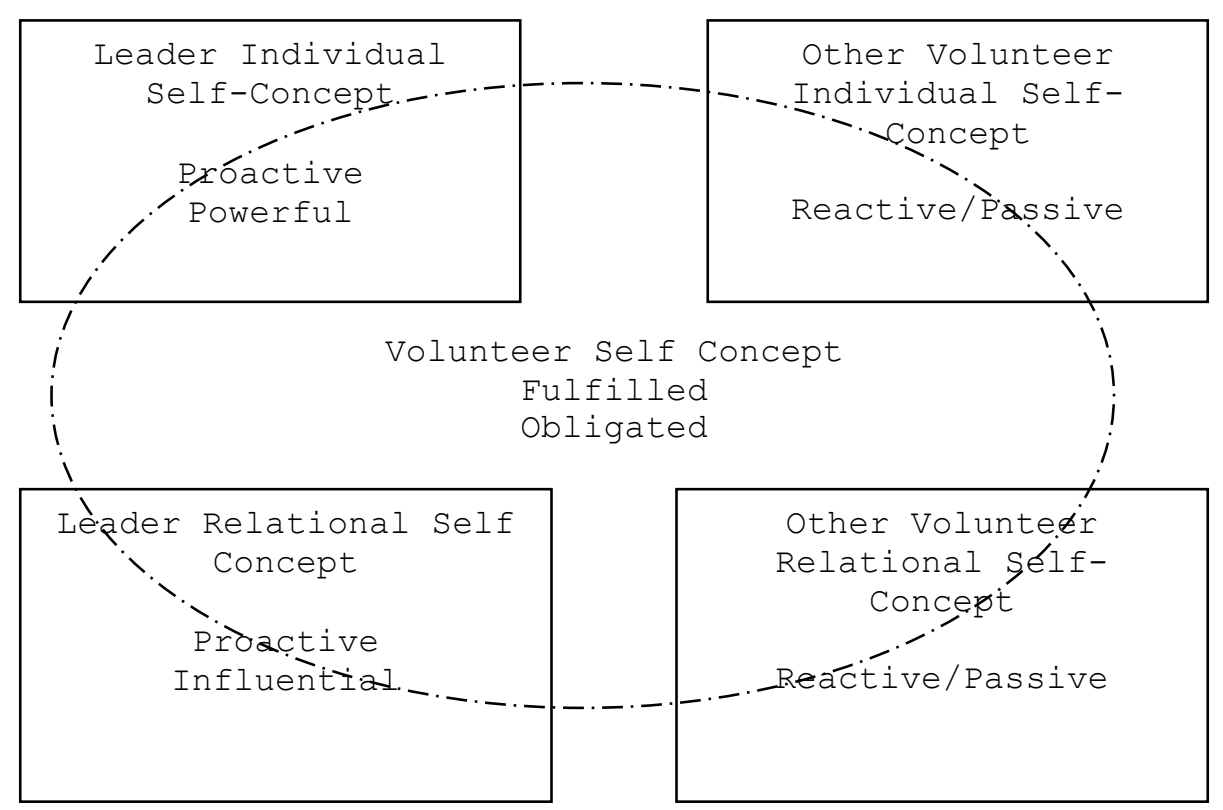


Table 1

Healthcare Organization Participant Profiles

\begin{tabular}{|c|c|c|c|}
\hline $\begin{array}{l}\text { Qualitative } \\
\text { Method }\end{array}$ & Participants & Demographics & Relationship \\
\hline $\begin{array}{l}\text { Focus } \\
\text { Group }\end{array}$ & $\begin{array}{l}6 \text { Volunteers that were } \\
\text { considered effective by } \\
\text { volunteer co-ordinator }\end{array}$ & $\begin{array}{l}5 \text { female } \\
1 \text { male } \\
3 \text { retired pensioners } \\
2 \text { disability pensions } \\
\text { prior positions include } \\
\text { teaching, administrative, } \\
\text { auto hourly } \\
\text { both disability pensioners } \\
\text { former patients }\end{array}$ & Volunteers \\
\hline $\begin{array}{l}\text { Focus } \\
\text { Group }\end{array}$ & $\begin{array}{l}5 \text { Team leader } \\
\text { volunteers }\end{array}$ & $\begin{array}{l}4 \text { female } \\
1 \text { male } \\
5 \text { retired pensioners } \\
3 \text { prior employees } \\
140 \text {-year volunteer } \\
1 \text { retired supervisor from } \\
\text { auto industry }\end{array}$ & Volunteers \\
\hline Interview & Training Coordinator & Male & Volunteer \\
\hline $\begin{array}{l}\text { Group } \\
\text { interview }\end{array}$ & $\begin{array}{l}\text { 1) Gift Shop Manager } \\
\text { and 2) Temporary } \\
\text { Volunteer Co-ordinator }\end{array}$ & 2 female & Employees \\
\hline Interview & $\begin{array}{l}\text { Volunteer Co-ordinator } \\
\text { and }\end{array}$ & Female & Employee \\
\hline Interview & $\begin{array}{l}\text { Director of Mission, } \\
\text { Pastoral and Volunteer } \\
\text { Services }\end{array}$ & Female & Employee \\
\hline Interviews & $\begin{array}{l}5 \text { Supervisors of } \\
\text { volunteers on various } \\
\text { floors }\end{array}$ & $\begin{array}{l}4 \text { female } \\
1 \text { male } \\
2 \text { administrators, } 1 \text { Renal } \\
\text { Dialysis, Eye Surgery } \\
\text { Clinic, Priest Chaplain }\end{array}$ & Employees \\
\hline Total & 22 participants & $\begin{array}{l}17 \text { females } \\
5 \text { males }\end{array}$ & $\begin{array}{l}9 \text { employees } \\
13 \text { volunteers }\end{array}$ \\
\hline
\end{tabular}


Table 2

Comparison of Volunteer Leaders and Other Volunteers

\begin{tabular}{|c|c|c|}
\hline Theme & Volunteer Leader & Other Volunteers \\
\hline \multicolumn{3}{|c|}{ Individual Level } \\
\hline & Proactive & Passive/Reactive \\
\hline $\begin{array}{l}\text { Self-relevant Information } \\
\text { Processing (Training and } \\
\text { Development) }\end{array}$ & $\begin{array}{l}\text { Actively seek out training to } \\
\text { meet needs of hospital }\end{array}$ & $\begin{array}{l}\text { Fit current skills into needs } \\
\text { of hospital }\end{array}$ \\
\hline $\begin{array}{l}\text { Affect Regulation (Coping } \\
\text { Strategies) }\end{array}$ & $\begin{array}{l}\text { Personal development as a } \\
\text { coping strategy for } \\
\text { emotionally challenging } \\
\text { roles, seeking out leadership } \\
\text { roles or training }\end{array}$ & $\begin{array}{l}\text { Important of fit between } \\
\text { person and emotional } \\
\text { demands of role. }\end{array}$ \\
\hline $\begin{array}{l}\text { Motivation } \\
\text { (Previous Experience) }\end{array}$ & $\begin{array}{l}\text { Previous jobs shaped } \\
\text { personal power in expanding } \\
\text { volunteering role }\end{array}$ & $\begin{array}{l}\text { Previous jobs provided } \\
\text { skills that allowed better } \\
\text { fit. }\end{array}$ \\
\hline \multicolumn{3}{|c|}{ Relational Level } \\
\hline & Proactive & Passive / Reactive \\
\hline $\begin{array}{l}\text { Self reflected through } \\
\text { Union }\end{array}$ & Active conflict resolution & Passive conflict response \\
\hline $\begin{array}{l}\text { Self reflected through Paid } \\
\text { Employees }\end{array}$ & $\begin{array}{l}\text { Complaining: Unappreciated } \\
\text { by employees }\end{array}$ & $\begin{array}{l}\text { Satisficing: Appreciated by } \\
\text { employees }\end{array}$ \\
\hline $\begin{array}{l}\text { Self reflected through } \\
\text { Patients }\end{array}$ & \multicolumn{2}{|c|}{ Feedback and Interaction (gratitude) } \\
\hline $\begin{array}{l}\text { Self reflected through } \\
\text { Other Volunteers }\end{array}$ & $\begin{array}{l}\text { Communication of important } \\
\text { job-related information } \\
\text { No influence tactics }\end{array}$ & $\begin{array}{l}\text { Participation in Social } \\
\text { Gatherings } \\
\text { No influence tactics }\end{array}$ \\
\hline $\begin{array}{l}\text { Self reflected through } \\
\text { Institution }\end{array}$ & \multicolumn{2}{|c|}{$\begin{array}{l}\text { Previous experiences with the institution shaped a view of } \\
\text { volunteering as a way to give back }\end{array}$} \\
\hline
\end{tabular}

